\title{
ОБРАЗОВАНИЕ
}

\author{
В.И. Левин
}

\section{Новая программа образовательной подготовки аспирантов}

Аннотация. Рассматривается проблема образовательной подготовки аспирантов и соискателей в России. Описываются действуюшие в настоящее время в мире системы образовательной подготовки, их достоинства и недостатки. Основное внимание уделяется системам подготовки, действующим в Германии, Франции, Великобритании и США. Описывается и анализируется также сложившаяся во времена СССР система подготовки аспирантов, сохранившаяся в современной России. Предложена новая система образовательной подготовки российских аспирантов, отличающ,аяся программой подготовки, ориентированной на современные задачи российской высшей школы. В программу входят: история научных открытий, логика и критическое мышление, методика научных исследований, культура научной деятельности, научная этика, основы права.

Работа базируется на анализе трудов отечественных и зарубежных учёных - специалистов в области подготовки кадров, а также методических работ научных руководителей аспирантов. Широко использованы некоторые отечественные и зарубежные работы по истории науки, методике научных исследований, логике, культуре научной деятельности, научной этике, методике подготовки диссертаций и статей.

Основные выводы: 1) введение в России трёхступенчатой системы высшего образования (бакалавриат, магистратура, аспирантура) открывает потенииальную возможность улучшения образовательной подготовки российских аспирантов; 2) в мире существуют разные образовательные школь для аспирантов, отличающиеся программой и национальными традициями; 3) современная образовательная подготовка российских аспирантов не обеспечивает им получения хорошего образования и общей культурь; 4) для улучшения образовательной подготовки аспирантов необходим пересмотр программ их обучения.

Ключевые слова: образовательная подготовка, аспирант, научно-образовательная школа, аспирантура в России, новая образовательная программа, трёхступенчатая система образования, методика исследованици, культура исследователя, научная этика, история науки.

Abstract. The article is devoted to the problem of educational training of graduate students and PhD students in Russia. The researcher describes the current systems of educational training in the world and focuses on their pluses and minuses. Special attention is paid to the systems of training in Germany, France, Great Britain and USA. The author also describes and analyzes the system of graduate training which was formed in the USSR and is still efficient in today's Russia. The author offers a new system of educational training of Russian graduates. This program is oriented at modern tasks and goals of Russian higher education. The curriculum includes: history of scientific discoveries, logic and critical thinking, research methods, investigation culture, academic ethics and law basics. The research is based on the analysis of both Russian and foreign researches conducted by specialists in the sphere of personnel training as well as methodological works of graduates' research advisors. Levin has also used a lot of Russian and foreign researches on the history of science, methods of scientific research, logic, investigation culture, academic ethics, methods of writing thesis research and articles. The main conclusions are the following: 1) introduction of the three-stage educational system in Russia (bachelor's, master's programs and graduate (PhD) studies) offers a good opportunity to improve training of Russian graduates; 2) there is a great variety of educational schools for graduates all over the world, each school having its own curriculum and national traditions; 3) the current system of training Russian graduates provides neither a good education nor a decent overall cultural level of students; 4) in order to improve the system of graduate studies, it is necesary to review their programs and curricula. 
Keywords: history of science, three-stage educational system, new educational program, graduates in Russia, scientific-educational school, graduate student, educational training, research methods, investigation culture, academic ethics.

\section{1. Введение}

егодня ни у кого не вызывает сомнения большая роль качественной подготовки студентов в вузе. Такая подготовка позволяет вырастить из студента хорошего специалиста и культурного человека, способного всю жизнь учиться и, если нужно, переучиваться, приобретая новую профессию и приспосабливаясь к новым реалиям окружающей жизни. Ещё большее значение сегодня имеет образовательная подготовка аспирантов и соискателей, поскольку она, в дополнение к задачам, ставящимся перед образовательной подготовкой студентов, должна помочь аспирантам и соискателям подготовить и защитить диссертацию, а затем успешно работать в качестве педагога высшей школы, осуществляя образовательную подготовку будущих специалистов.

Образовательная подготовка аспирантов и соискателей, в той или иной форме, существует как в России, так и за рубежом уже давно. Однако такая подготовка традиционно всегда носила вспомогательный характер. Главным же делом аспиранта и соискателя считались подготовка и защита диссертации. Но в последнее время Россия, следуя примеру Европы, ввела у себя трёхступенчатую систему высшего образования (бакалавриат, магистратура, аспирантура). Тем самым аспирантура в России из формы послевузовского образования уже превратилась в третью ступень вузовского образования. Это означает радикальное изменение ситуации с подготовкой российских аспирантов, поскольку теперь аспирантура - всего лишь образовательный модуль, равноправный с другими модулями (бакалавриатом и магистратурой) и отличающийся от них лишь формой отчётности (диссертация вместо экзамена) и формой управления (один научный руководитель в среднем на 5 аспирантов вместо одного куратора группы, состоящей в среднем из 20-25 человек). Такое радикальное изменение института аспирантуры, конечно, сильно снижает его статус. Однако, наряду с отрицательными последствиями проведённого реформирования, имеются и положительные. Главное из них - открывающаяся потенциальная возможность, используя новый, образовательный статус нашей аспирантуры, существенно расширить и улучшить образовательную подготовку российских аспирантов. И этой возможностью надо обязательно воспользоваться.

\section{2. Образовательная подготовка аспирантов в мире}

За рубежом образовательная подготовка аспирантов сложилась значительно раньше, чем аналогичная подготовка в России. За долгие годы её существования были выработаны не только общие принципы подготовки, но и созданы основные научно-образовательные школы, отличающиеся друг от друга воплощенными в них программами подготовки и определёнными национальными традициями. Сегодня существуют три такие школы [1]:

1. Германская (включающая Австрию, Германию, Данию, Нидерланды, Швейцарию и Швецию);

2. Французская (включающая Бельгию, Италию, Францию, Тунис и др.);

3. Англосаксонская (включающая Англию, Ирландию, Канаду, США, Турцию, страны Восточной Европы).

Также, независимо от принадлежности к той или иной научно-образовательной школе, все университеты вынуждены предусматривать подготовку молодых исследователей с учётом новой, инновационной экономики. С этой целью многие университеты вводят для них образовательные программы, включающие курсы, направленные на развитие исследовательских, профессиональных и персональных навыков (методики исследовательской работы, подготовка публикаций, научная этика, межличностная коммуникация, работа в коллективе и лидерство, интеллектуальная собственность, управление инновациями, финансовый менеджмент, управ- 


\section{Педагогика и просвещение 4(20) • 2015}

ление персоналом). Конкретное воплощение программ образовательной подготовки аспирантов зависит от страны и университета, в котором они реализуются.

В Германии (и, в той или иной степени, в других странах, принадлежащих к германской научно-образовательной школе подготовки аспирантов) достижение высшей научной квалификации - степени доктора философии - предполагает (кроме защиты диссертации) сдачу нескольких экзаменов для оценивания достигнутого уровня освоения нескольких общих и специальных дисциплин. Эти дисциплины изучаются в рамках соответствующего образовательного контента в форме семинаров и коллоквиумов. Кроме того, аспиранты должны подготовиться по всему курсу, соответствующему их специальности (независимо от темы диссертации), и сдать соответствующий экзамен перед комиссией профессоров. В качестве экзамена может быть использована сама защита диссертации в традиционной форме или лекция соискателя по теме диссертации и последующая дискуссия. В последние годы для подготовки аспирантов стали создаваться специальные так называемые университетские градуальные колледжи, которые представляют собой целевые исследовательские группы для соискателей докторской степени. Эти колледжи имеют структурированные программы подготовки и полностью финансируются из госбюджета. Учащиеся колледжей ведут диссертационные исследования и параллельно посещают общие и специальные образовательные курсы (4-6 часов в неделю). Специалисты считают такие колледжи лучшим средством преодоления имеющихся недостатков в подготовке исследователей и преподавателей вузов.

Во Франции (и, в определённой степени, в других странах, принадлежащих к французской школе подготовки аспирантов) подготовка аспирантов по докторским программам проводится в так называемых докторских школах при университетах. Каждая школа открывается по согласованию с Министерством образования и науки, с оформлением контракта на 4 года. У каждой докторской школы есть соответствующий научный проект, отвечающий перспективному плану развития университета. Докторские школы вербуют претендентов для обучения в аспирантуре, организуя для них подготовительные курсы, семинары и т.д. Французская система подготовки аспирантов предполагает наличие у претендентов достаточного для обучения в аспирантуре уровня образования. Конкретно, для поступления в аспирантуру надо иметь диплом магистра либо специальный «исследовательский» диплом, выдаваемый после окончания специального университетского исследовательского цикла. Особых образовательных программ, которые обязательны для аспирантов во время обучения в аспирантуре, не предусматривается. Считается, что необходимый уровень образования аспиранты получают заранее, во время обучения в магистратуре или прохождения университетского исследовательского цикла, а в аспирантуре они полностью «погружаются» в диссертационное исследование.

В Великобритании осуществляется традиционная форма англосаксонской школы подготовки аспирантов, характеризуемая большой свободой выбора и связанной с этим эклектичностью программ. При этом, кроме общепринятой подготовки аспирантов по докторским программам, в последние годы всё шире распространяется программа New Route PhD, которая уделяет повышенное внимание образовательной подготовке аспирантов в области их специализации. Особенность этой программы и в том, что она предусматривает проведение научных исследований и, параллельно этому, обучение дисциплинам, посвящённым овладению методами исследования. Как правило, аспирант усваивает выбранные им образовательные курсы и овладевает необходимыми профессиональными навыками исследователя в течение первых двух лет аспирантуры. При этом он совмещает обучение с исследовательской работой. В заключительные два года аспирантуры всё его внимание переключается на работу над диссертацией. Одной из особенностей подготовки аспирантов в стране является большой процент работающих аспирантов. В их интересах создаются специальные заочные формы подготовки по гибким индивидуальным программам.

В США (и большинстве других стран, принадлежащих к англосаксонской школе подготовки 
аспирантов) аспирантура является надежной опорой всего процесса научных исследований в стране. При этом успешное развитие науки и технологий в большой степени обеспечивается хорошими условиями, которые создаются для выпускников аспирантуры, получивших докторскую степень (PhD). Американские программы подготовки аспирантов пользуются большой популярностью как американских, так и иностранныхучащихся, поскольку они имеют широкую номенклатуру научных специальностей, хорошо адаптированы к запросам учащихся и хорошо обеспечиваются финансово. Многие иностранцы - выпускники американской аспирантуры - по окончании обучения не возвращаются на родину, а остаются работать в США. Это способствует повышению интеллектуального потенциала страны. Типовая программа аспирантской подготовки в США начинается с двухлетней образовательной подготовки, включающей лекционные курсы, а также практические и лабораторные работы. Образовательная подготовка содержит базовый и дополнительный материал в области специализации аспиранта, методологию исследования и выполнения диссертации. После изучения этого материала предусматриваются экзамены в устной и письменной форме. После сдачи экзаменов аспирант приступает к подготовке диссертации, которая обычно продолжается два года.

Итак, действующие в настоящее время системы общеобразовательной подготовки аспирантов в зарубежных странах обеспечивают им получение хорошего образования, характеризуемого приличными знаниями в области специализации аспиранта и методологии научных исследований. Это помогает сформировать из обучаемого квалифицированного учёного, способного выполнять научные исследования на хорошем современном уровне. Однако это образование не позволяет подготовить человека достаточно высокой общей культуры, способного быть хорошим педагогом высшей школы.

\section{3. Образовательная подготовка аспирантов в России}

Действующая сегодня система образовательной подготовки аспирантов и соискателей в России возникла ещё в СССР и с тех пор при- нципиально не менялась. Эта система включает изучение двух образовательных дисциплин: 1) иностранный язык (английский или немецкий или французский); 2) философия и история науки. В некоторых (далеко не во всех) вузах преподаются ещё 3) основы научных исследований. Рассмотрим кратко содержание и методику преподавания указанных дисциплин.

Преподавание иностранного языка для аспирантов и соискателей в России осуществляется силами кафедр иностранных языков вузов и научных институтов. Оно направлено на дальнейшее повышение уровня знаний языка у аспирантов и соискателей, по сравнению с уровнем, достигаемым ими по окончании вуза. В некоторой (небольшой) степени это преподавание направлено также на освоение профессионального языка в области, в которой специализируется аспирант (соискатель). Но главное, на что делается упор, - это подготовка аспирантов и соискателей к сдаче кандидатского экзамена по иностранному языку. Основные недостатки описанного подхода к преподаванию иностранного языка для аспирантов (соискателей) заключаются в том, что 1) учащихся учат, в основном, общелитературному иностранному языку, в то время как упор должен делаться на профессиональный язык, связанный с предметной областью, в которой специализируется учащийся, а это нечто другое; 2) учащихся не учат написанию научных статей, выступлениям на научных конференциях, переписке с коллегами и редакциями журналов на иностранном языке. Эти недостатки неизбежны и вызваны тем, что работники кафедр иностранных языков в большинстве своём не знакомы ни с профессиональными версиями иностранных языков, ни с практикой их использования в различных задачах научной деятельности.

Преподавание философии и истории науки для аспирантов и соискателей в стране обычно ведётся силами кафедр философии вузов и научных институтов. Оно имеет своей целью пополнить и развить знания по философии, полученные учащимися на младших курсах вузов, и в некоторой степени познакомить их с философией науки. Что касается истории науки, то она чаще всего не рассматривается вовсе. В этом состоит главный недостаток преподавания 


\section{Педагогика и просвещение 4(20) • 2015}

курса «Философия и история науки», поскольку именно история науки является исходной, базовой дисциплиной для будущих учёных всех специальностей, подобно тому, как история философии является общепризнанной исходной, базовой дисциплиной для будущих философов, независимо от их специализации. Указанный недостаток неизбежен и вызван тем, что работники кафедр философии, как правило, не занимаются историей науки и не знают её. А вот преподаваемая ими философия, включающая философию науки, для большинства будущих учёных оказывается невостребованной в их практической деятельности. Вообще, кафедры философии в современной России в большинстве случаев являются наследницами кафедр марксистской философии в СССР, занимавшихся так называемым диалектическим и историческим материализмом, который в современной мировой науке квалифицируется как лженаука [2]. И это наследство настораживает.

Преподавание дисциплины «Основы научных исследований» для аспирантов и соискателей в России не имеет одной определённой базовой кафедры, силами которой оно бы повсеместно осуществлялось. Связано это с тем, что данная дисциплина не имеет чётко очерченной программы. Можно лишь сказать, что обычно эта программа включает некоторый набор базовых математических методов (чаще всего вероятностно-статистических), составляющих в совокупности методологию исследования нескольких классов систем (в основном, технических). В связи с этим преподавание дисциплины «Основы научных исследований» чаще всего ведут сотрудники математических, информационных и других, родственных им, кафедр, а также члены соответствующих диссертационных советов, работники научно-исследовательских отделов вузов и т.д. Так что на практике содержание курса указанной дисциплины отражает в основном вкусы и специализацию преподавателей, а не научную специальность слушателей. В этом состоит главный недостаток преподавания курса «Основы научных исследований». Другой недостаток заключается в том, что преподавателей данного курса специально нигде не готовят, в результате чего зачастую этот курс ведут люди низкой квалификации, обладающие вдобавок низкой общей культурой.

Итак, действующая в настоящее время система образовательной подготовки аспирантов и соискателей в России, к сожалению, на деле не обеспечивает им получение хорошего образования в области специализации аспиранта, методологии научных исследований и общей культуры. Она не даёт обучаемым широких и глубоких знаний, помогающих формировать из них хороших учёных и педагогов высшей школы.

\section{4. Какой должна быть образовательная подготовка российских аспирантов}

При разработке программ образовательной подготовки аспирантов в России следует, очевидно, исходить из общих целей этой подготовки. На наш взгляд, общие цели подготовки российских аспирантов заключаются в следующем.

1. Формирование квалифицированных научных работников, способных выполнять научные исследования на передовом современном уровне и получать новые научные результаты;

2. Подготовка квалифицированных педагогов высшей школы, способных обучать студентов на современном научно-методическом уровне и обеспечивать их выпуск;

3. Формирование самостоятельных, независимо мыслящих людей и специалистов;

4. Воспитание обучаемого в духе соблюдения норм научной и профессиональной этики, в том числе, на примерах жизни и деятельности великих учёных прошлого;

5. Формирование людей, обладающих чётким правовым сознанием, готовых участвовать в построении гражданского общества в своей стране.

В соответствии с этими целями минимально необходимый перечень общеобразовательных дисциплин для изучения российскими аспирантами и соискателями всех специальностей должен, по нашему мнению, включать следующие дисциплины:

1. История научных открытий в лицах;

2. Логика и критическое мышление;

3. Методика научных исследований;

4. Культура научной деятельности;

5. Научная этика; 
6. Основы права и гражданское общество.

Рассмотрим теперь кратко содержание каждой из предлагаемых дисциплин подготовки аспирантов.

Дисциплина «История научных открытий в лицах» излагает историю и суть важнейших открытий на фоне биографий выдающихся учёных-авторов этих открытий. Она отличается от известной дисциплины «История науки» тем, что в центре её внимания находятся не столько открытия, сколько их творцы - учёные и живые люди, со своими человеческими достоинствами и недостатками. Такое изложение материала способствует пробуждению у слушателей интереса к науке, их воспитанию в духе соблюдения норм научной этики, восприятию передовых методик исследования и, в конечном счёте, формированию из них квалифицированных учёных и педагогов высшей школы. Слушатели получают возможность выбрать среди учёных-корифеев образец для подражания в жизни, что может оказаться для них очень важным и даже решающим.

Дисциплина «Логика и критическое мышление» излагает так называемую практическую логику, а также сложившееся в США в последние десятилетия логическое направление, получившее название «критическое мышление». Практическая логика отличается от известной дисциплины «Математическая логика» тем, что учит не только делать логически правильные выводы из известных посылок, но и отыскивать такие посылки, выводы из которых могут содержать новые знания. Поня тно, что наука развивается, обрастая новыми знаниями, при помощи именно практической логики. Критическое мышление, в отличие от собственно логики, учит составлять достаточно убедительные (но не обязательно на все $100 \%$ !) обоснования правильности суждений, высказанных на основе интуиции. В целом дисциплина «Логика и критическое мышление» обучает составлению правильных суждений и проверке правильности уже составленных суждений, способствуя этим освоению аспирантами более продвинутых методик исследования. Эта дисциплина также весьма полезна в практической жизни, поскольку помогает грамотно анализировать различные жизненные ситуации и на этой основе принимать логически обоснованные, правильные решения.

Дисциплина «Методика научных исследований» излагает разнообразные методологии и приёмы научных исследований, которые носят универсальный характер, т.е. применимык различным наукам и научным направлениям - естественным, точным, гуманитарным, общественным. Таковы, например, методы обработки данных, методы установления зависимостей, методы математического моделирования; разнообразные приёмы, облегчающие решение высокоразмерных сложных задач - декомпозиция, композиция, мозговой штурм; существующие подходы кучёту неопределённости изучаемых систем - вероятностно-статистические, нечётко-множественные, интервальные. В состав данной дисциплины могут включаться также и некоторые неуниверсальные методологии и приёмы научных исследований, которые оказались весьма эффективными применительно к каким-то конкретным наукам и в связи с этим вызвали интерес представителей других наук. Таковы, например, теория научного эксперимента, теория игр и др.

Дисциплина «Культура научной деятельности» включает в себя описание различных видов деятельности научного работника, которые, не являясь собственно научной деятельностью, способствуют успеху таковой, причём тем в большей степени, чем выше культура их выполнения. Примерами указанных видов деятельности являются: ознакомление с новыми научными публикациями, ведение систематической картотеки научных публикаций, установление научных контактов с другими учёными, подготовка собственных публикаций (включая подготовку публикаций в зарубежных журналах на иностранных языках), подготовка и оформление диссертационной работы, подготовка разнообразных документов, проектов отзывов и т.д.

Дисциплина «Научная этика» содержит основополагающие сведения о необходимой социальной ответственности поведения учёных, при которой обеспечивается недопущение отрицательного влияния науки на права, 


\section{Педагогика и просвещение 4(20) • 2015}

достоинство и здоровье человека. Излагается также содержание основных международных документов, регламентирующих соблюдение норм социально ответственного поведения учёных, занимающихся исследовательской и инженерно-конструкторской деятельность таких, как рекомендации ЮНЕСКО «О статусе научно-исследовательских работников» (Париж, 20.11.1974), «Декларация о науке и использовании научного знания» (Будапешт, 02.07.1999), «Заявление о добросовестности в исследованиях» (Сингапур, 15.07.2010), «Декларация об этических принципах научной деятельности в СНГ» (15.04.2012).

Дисциплина «Основы права и гражданское общество» содержит основные сведения о правовой системе России и её основных законах (Конституция РФ, Гражданское право и др.). В рамках преподавания этой дисциплины обучаемые должны быть хорошо ознакомлены с правами и обязанностями, которыми их наделяет российское законодательство, и обучены жить и действовать строго в рамках соответствующего правового поля. По окончании аспирантуры, став преподавателями высшей школы, они должны будут передать свои знания и навыки в этой области студентам. Это поможет созданию в стране развитого гражданского общества.

\section{5. Заключение}

Итак, в настоящее время открывается потенциальная возможность, используя новый, образовательный статус нашей аспирантуры, значительно расширить и улучшить образовательную подготовку российских аспирантов. Для реализации соответствующей образовательной программы, по-видимому, потребуется создание новых кафедр в вузах - кафедр образовательной подготовки аспирантов (ОПА). К счастью, создание таких кафедр сегодня не составит большого труда, поскольку специалисты, способные вести необходимые образовательные курсы (типа описанных в $\S 4)$, в российских вузах и НИИ пока ещё есть. Готовятся (либо уже есть) соответствующие учебные пособия [3-8]. Однако небольшое финансирование из бюджета для реализации указанной программы, соответствующее объёму программы и числу аспирантов в стране, потребуется. Мы не знаем, готово ли правительство РФ к такому финансированию. Известно лишь, что оно сделало первый шаг на пути к «облегчению» финансирования, существенно сократив число бюджетных мест в аспирантуре на 2015/16 учебный год. Будем надеяться, что оно не сделает следующего шага, «оптимизировав» объём аспирантской образовательной подготовки.

\section{Список литературы:}

1. Бедный Б.И., Миронос А.А. Подготовка научных кадров в высшей школе. Н. Новгород: Изд-во ННГУ, 2008. 220 с.

2. Logic in Central and Eastern Europe: History, Science, Discourse / Ed. A. Schumann. New-York: American University Press, 2013. 730 p.

3. Райзберг Б.А. Диссертация и учёная степень. М.: Инфра-М, 2008. 480 с.

4. Научные работы: методика подготовки и оформления / Сост. И.Н. Кузнецов. Минск: Амалфея, 1998.

5. Селье Г. От мечты к открытию. Как стать учёным. М.: Прогресс, 1998.

6. Кузин Ф.А. Диссертация. Методика написания. Правила оформления. Порядок защиты. М.: Ось89, 2001.

7. Левин В.И. История научных открытий. Т. 1. (Классика). Пенза: Изд-во ПензГТУ, 2010. 215 с.; Т. 2. (Современность). М.: Полина, 2012.370 с.

8. Левин В.И. Публикация статей за рубежом. Пенза: Изд-во ПензГТУ, 2015. 80 с. 


\section{References (transliteration):}

1. Bednyi B.I., Mironos A.A. Podgotovka nauchnykh kadrov v vysshei shkole. N. Novgorod: Izd-vo NNGU, 2008. $220 \mathrm{~s}$.

2. Logic in Central and Eastern Europe: History, Science, Discourse / Ed. A. Schumann. New-York: American University Press, 2013. 730 p.

3. Raizberg B.A. Dissertatsiya i uchenaya stepen'. M.: Infra-M, 2008. 480 s.

4. Nauchnye raboty: metodika podgotovki i oformleniya / Sost. I.N. Kuznetsov. Minsk: Amalfeya, 1998.

5. Sel'e G. Ot mechty k otkrytiyu. Kak stat' uchenym. M.: Progress, 1998.

6. Kuzin F.A. Dissertatsiya. Metodika napisaniya. Pravila oformleniya. Poryadok zashchity. M.: Os'-89, 2001.

7. Levin V.I. Istoriya nauchnykh otkrytii. T. 1. (Klassika). Penza: Izd-vo PenzGTU, 2010. 215 s.; T. 2. (Sovremennost'). M.: Polina, 2012.370 s.

8. Levin V.I. Publikatsiya statei za rubezhom. Penza: Izd-vo PenzGTU, 2015. 80 s. 